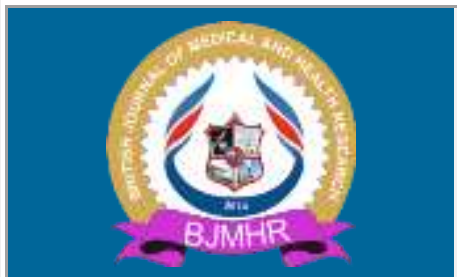

\title{
BJMHR
}

British Journal of Medical and Health Research Journal home page: www.bjmhr.com

\section{A Review On Probable Mode of Action of Herbal Formulation for Piles- Pylee}

\author{
Darshani Sonavaria*, Dr. Chetna Chotalia, Kavita Salkar, Rajiv Salvi \\ Piramal Phytocare Limited, Light Hall - A wing, Saki Vihar Road, Chandivali, Andheri - \\ (E), Mumbai-400 072, Maharashtra, India.
}

\begin{abstract}
Piles is a medical condition known as haemorrhoids wherein the veins inside or outside the anus or lower rectum gets inflamed or swollen. Symptoms of piles include feeling of soreness, irritation or pain while passing stool accompanied with bleeding. It is generally caused by faulty diet and genetic tendencies. Constipation and piles are interrelated, with one aggravating the condition of other. Hemorrhoids is a common anorectal disorder that hampers the daily activity of suffered person and imposes embarrassment associated with it. To review possible mode of action of herbal formulation for piles. Herbal formulation containing unique combination of five plant based ingredients like Azadirachta indica, Terminalia chebula, Symplocos racemosa, Curcuma longa and Glycyrrhiza glabra are beneficial in piles management which helps to control bleeding, prolapse, pain and mucus discharge, and reduces the size of the pile mass in all degrees of piles. A product with multi ingredient, each with a different activity profile would be an ideal product for piles management. This natural herbal formulation is safe and efficacious for piles and anorectal disorders.
\end{abstract}

Keywords: Piles, Haemorrhoids, Anorectal disorders, Herbal Anti Haemorrhoidal formulation, Phytoformulation, Pylee 


\section{INTRODUCTION}

Haemorrhoidal cushions, present in healthy individuals are vascular structures in the anal canal. They are masses, clumps, cushions of tissue in the anal canal which are full of blood vessels, support tissue, muscle and elastic fibers. In their normal state, they are cushions that help with stool control. They become a disease when swollen or inflamed and cause symptoms like prolapsed, pain, bleeding etc. Thus, the term 'haemorrhoids' or 'piles' is an embarrassing gastrointestinal disorder. When these normal cushions enlarge and get pushed downwards, producing symptoms - the disease is called as haemorrhoids. The word "haemorrhoid" is derived from the Greek word 'haema' (blood) and 'rhoos' (flowing), and implies the flow of blood from the veins of the anus. The term "piles" is derived from the Latin word "pila" (a ball). There are two types of piles-Internal and External haemorrhoids.

Worldwide, the prevalence of symptomatic haemorrhoids is estimated at $4.4 \%$ in the general population. The prevalence of haemorrhoids increases with age, with a peak in persons aged 45-65 years. Haemorrhoids is one of the most common gastrointestinal disease. This condition is common ailment among the adults. Men and women aged more than 50 years will experience hemorrhoid symptoms at least once during their lifetime. However, there have been incidences where children and the elderly have also been diagnosed with this condition. Hemorrhoid disease is said to be the fourth leading outpatient gastrointestinal diagnosis ${ }^{3}$. An individual with piles may experience symptoms like a hard lump may be felt around the anus consisting of coagulated blood, called a thrombosed external hemorrhoid which can be painful after emptying of bowels, a feeling that the bowels are still full, Bleeding on passing a stool, Itchiness or soreness around the anus, Mucus discharge from the anus when emptying the bowels, Pain while defecating and the area around the anus may be red and sore. The exact cause of symptomatic hemorrhoids is unknown. A number of factors are believed to play a role, including irregular bowel habits (constipation or diarrhoea), lack of exercise, nutritional factors (low fiber diet), increased intra abdominal pressure (prolonged straining, ascites, an intra abdominal mass or pregnancy), genetics, absence of valves within the haemorrhoidal veins, ageing and obesity.

Other factors includes prolonged sitting, a chronic cough, and pelvic floor dysfunction. The available products for piles management like laxatives, steroids, flavonoids have untoward reactions like abdominal cramps, diarrhoea, laxative addiction, and thinning of skin. Ayurveda ${ }^{4}$ offers several therapies for it. Variety of formulations in the form of creams, ointments, tablets and capsules are available in the market. Patients prefer taking tablets or capsules for instant relief from pain and irritation. Authors have selected an Ayurvedic capsule formulation named Pylee capsule for management of piles and other anorectal disorders. 
Pylee, a unique combination of five effective plant based ingredients like Azadirachta indica, Terminalia chebula, Symplocos racemosa, Curcuma longa and Glycyrrhiza glabra. Pylee is a product of Piramal Phytocare Limited, India.

Various chemical constituents from these plants are isolated and studied for their pharmacological effects. The product is duly studied for its efficacy and safety in patients suffering from piles. "Pylee" is a natural remedy for management of haemorrhoids.

Pylee can be presented as an effective option for haemorrhoids. Pylee is formulated using well known plants documented for their proved actions in a scientific way. The plant extracts present in the product are - Azadirachta indica, Terminalia chebula, Symplocos racemosa, Curcuma longa and Glycyrrhiza glabra which helps in treating piles naturally.

\section{MATERIALS AND METHOD}

\section{Azadirachta indica (Neem bark) extract}

Since time immemorial $\mathrm{Neem}^{5}$ has been used by Indian people for treatment of various diseases due to its excellent medicinal properties. Nimbidin ${ }^{6}$, Azadirachtin and Epoxy azadiradione are the active compounds present in Neem which are responsible for antibacterial activity. Azadirachta indica possesses antibacterial and antiseptic properties by effectively active against a wide spectrum of bacteria viz., S. aureus, E. coli, P. vulgaris, S. dysenterae, Enterococcus faecalis and even resistant strains associated with secondary infection associated with haemorrhoids.

The antibacterial action prevents secondary infection of infected tissues and thus promotes faster healing of the infected tissues. Thus, exhibiting astringent property. The unripe fruit acts as a purgative and helps to heal piles. Epoxy azadiradione shows the anti-inflammatory activity against macrophage migration inhibitory factor.

Thus, it has anti-inflammatory and pain-relieving properties. Neem helps to prevent haemorrhoids by promoting the elimination of waste, and avoiding constipation. It arrests bleeding i.e imparting antihemorrhagic activity by strengthening vein walls and hence helps to cure bleeding piles.

Nimbidine and Azadirachtin possesses analgesic activity. The analgesic effect shown is preferably by inhibition of prostaglandin synthesis, a peripheral mechanism of pain inhibition. It acts on the mediators which include prostaglandins, especially the E series, histamine, bradykinins, leucotrienes and serotonin, all of which also cause pain and fever. Thus, it is effective in acute inflammatory conditions associated with haemorrhoids.

Therefore, the above various properties of Azadirachta indica ${ }^{7}$ like Antihemorrhagic action, Analgesic, Anti-inflammatory, Anti microbial, Astringent, laxative, purgative action helps in the management of haemorrhoids by controlling bleeding and pain. 


\section{Terminalia chebula (Haritaki) extract}

Haritaki is called the "king of medicines ${ }^{8 "}$ because of its extraordinary powers of healing. Terminalia chebula is excellent for the digestive system.

Gallic acid and Chebulagic acid are the tannins present in Terminalia chebula which works to cure constipation, improves digestion and gastro intestinal motility of bowel by improving peristaltic movements and then slowly it helps to evacuate all toxic waste from the system along with faecal mass without any damage and purify the blood. Thus, exhibiting laxative activity.

The compounds increases the frequency of stools and has got the property of evacuating the bowel completely.

The oil present in the kernel of Terminalia chebula ${ }^{9}$ increases motility of the gastrointestinal tract with a protective effect on the gastrointestinal mucosa.

Chebulagic acid ${ }^{10}$ have anti-bacterial activity which helps to treat Haemorrhoids.

Chebulagic acid also helps to control bleeding associated with haemorrhoids. Chebulagic acid inhibits various inflammatory mediators like COX, LOX and TNF- $\alpha$ and thus have an antiinflammatory activity also.

Chebulagic acid promotes wound healing and helps to cure piles.

Chebulagic acid increases immune-histochemical, transcriptional, and translational levels of VEGF-A (vascular endothelial growth factor-A) expression, increases the amount of newly formed capillaries at the inflammatory phase as well as the percentage of wound contraction at the granulation formation and scar remoulding phases. In addition to promoting wound healing, when compared with erythromycin ointment or Vaseline, the compounds have a stronger angiogenic effect. It is therefore believed that tannin extracts promote wound healing, probably through their associated powerful angiogenic property.

Tannin extracts did not affect VEGF-A expression at the later stages of healing process, thereby resulting in the acceleration of wound maturity. The reason may be related to neovascularity, an indicator of immature granulation tissue, diminishing gradually with the maturing of wound. The compounds also decrease the permeability of capillaries in the wound and alleviate tissue edema and exudation, resulting in rapid scab formation. As a result, it can effectively prevent the invasion of foreign microbes, avoiding enlargement and development of the infected wound.

Therefore, the above properties of Terminalia chebula like Digestive action, Antihemorrhagic activity, wound healing, antioxidant, GI prokinetic action helps in the management of haemorrhoids by reducing intra abdominal straining and prolapse. 


\section{Symplocos racemosa (Lodra) extract}

Symposide ${ }^{11}$ and Ellagic acid are the compounds present in Symplocos racemosa. It is useful in bleeding piles, effective in wound healing and helps to stop haemorrhage.

Symposide, a new anti-fibrinolytic glycoside helps to control bleeding associated with piles. This compound interferes with the formation of the fibrinolytic enzyme plasmin from its precursor plasminogen. It is assumed to block the binding sites of the enzymes or plasminogen respectively and thus stop plasmin formation. Thus, it controls bleeding associated with piles. It reduces pain and edema. It also possesses laxative properties. The digestive action helps to control straining and hence the enlargement of the haemorrhoidal plexus.

Therefore, the above properties of Symplocos racemosa like Anti fibrinolytic activity, antiinflammatory helps in the management of haemorrhoids by controlling bleeding associated with piles.

\section{Curcuma longa (Haridra) extract}

Haridra is a powerful anti-inflammatory, antiseptic and also helps to stop bleeding. Curcumin is the compound present in Curcuma longa which inhibits various inflammatory mediators like COX, LOX and TNF- $\alpha$ and thus have an anti-inflammatory activity.

Curcumin have anti-bacterial activity which helps to treat Haemorrhoids by effectively active against a wide spectrum of bacteria viz., S. aureus, E. coli, P. vulgaris, S. dysenterae, Enterococcus faecalis and even resistant strains associated with secondary infection associated with haemorrhoids.

The antibacterial action prevents secondary infection of infected tissues and thus promotes faster healing of the infected tissues.

These compounds possess analgesic activity ${ }^{12}$ mediated through opioid receptors in laboratory animals.

The analgesic effect shown is preferably by inhibition of prostaglandin synthesis, a peripheral mechanism of pain inhibition. It acts on the mediators which include prostaglandins, especially the E series, histamine, bradykinins, leucotrienes and serotonin, all of which also cause pain and fever. Thus, it is effective in acute inflammatory conditions associated with haemorrhoids. Therefore, the above properties of Curcuma longa like Analgesic ${ }^{13}$, Anti -inflammatory, Anti -microbial helps in the management of haemorrhoids by reducing pain associated with piles.

\section{Glycyrrhiza glabra (Yastimadhu) extract}

Glycyrhiza glabra is a benefiting laxative that is generally prescribed to patients suffering from constipation. Glycyrrhizin and glycyrrhizic acid are the compounds present in Glycyrrhiza glabra.

Glycyrrhizin possesses laxative properties. 
Glycyrrhizin - which has a similar structure and activity same as the adrenal steroids has an anti-inflammatory activity similar to cortisone. This is due, in part, to inhibition of phospholipase A2 activity, an enzyme critical to numerous inflammatory processes.

Glycyrrhizic acid- inhibits cyclooxygenase activity and prostaglandin formation (specifically prostaglandin E2), as well as indirectly inhibits platelet aggregation, all factors responsible for the inflammatory process.

A flavonoid, isoliquiritigenin, from Glycyrrhiza glabra showed analgesic activity ${ }^{14}$ in acetic acid-induced writhing response and hot plate test at the high dose.

Therefore, the above properties of Glycyrrhiza glabra like Analgesic, Anti -inflammatory and laxative helps in the management of haemorrhoids by reducing pain associated with pain.

\section{RESULTS AND DISCUSSION}

\section{Comparison with competitors}

\section{Comparison with Topical treatments:}

Topical Anti Haemorrhoidal medications provides only symptomatic relief from haemorrhoids and there is little evidence to support their use. However, Pylee aims at the root cause of the disorder and frequent use of Pylee may prevent re-occurrence of piles.

In comparison with erythromycin ointment or Vaseline, the natural tannin compound of extract has a powerful angiogenic property which helps in promoting wound healing.

\section{Comparison with Topical Steroids}

Prolonged use of topical Steroids may irritate the anal area, causing local allergic effects like sensitization or thinning of the skin. Hence, cannot be used for more than two weeks.

\section{Use of Laxatives}

Frequent usage of laxatives is harmful, as it may create dependency causing abdominal cramps.

\section{Comparison with Allopathic medicines}

Allopathic medicines will only provide temporary relief from symptoms of painful piles with actions uncertain like abdominal pain, diarrhoea, head ache. They won't be able to provide any long lasting cure. They would actually worsen constipation and piles as a result.

Table 1: Different Mode of Action of Pylee Capsule

\begin{tabular}{|c|c|c|c|c|}
\hline Plant name & $\begin{array}{l}\text { Botanical } \\
\text { name }\end{array}$ & $\begin{array}{l}\text { Chemical } \\
\text { constituent }\end{array}$ & Action & Benefits \\
\hline Neem & $\begin{array}{l}\text { Azadirachta } \\
\text { indica }\end{array}$ & $\begin{array}{l}\text { Epoxy } \\
\text { azadiradione, } \\
\text { Nimbidine, } \\
\text { azadirachtin }\end{array}$ & $\begin{array}{l}\text { Antihemorrhagic } \\
\text { activity, } \\
\text { Analgesic, anti- } \\
\text { inflammatory, anti- } \\
\text { microbial, astringent, } \\
\text { laxative, purgative }\end{array}$ & $\begin{array}{l}\text { Controls } \\
\text { bleeding and } \\
\text { pain }\end{array}$ \\
\hline Haritaki & $\begin{array}{l}\text { Terminalia } \\
\text { chebula }\end{array}$ & $\begin{array}{l}\text { Gallic acid, } \\
\text { Chebulagic acid, }\end{array}$ & $\begin{array}{ll}\text { Digestive } & \text { action, } \\
\text { antioxidant, } & \text { wound }\end{array}$ & $\begin{array}{l}\text { Reduces intra } \\
\text { abdominal }\end{array}$ \\
\hline
\end{tabular}




\begin{tabular}{|c|c|c|c|c|}
\hline & & & $\begin{array}{l}\text { healing, antihemorrhagic } \\
\text { activity, GI prokinetic } \\
\text { action, }\end{array}$ & $\begin{array}{l}\text { straining and } \\
\text { prolapse }\end{array}$ \\
\hline Lodhra & $\begin{array}{l}\text { Symplocos } \\
\text { racemosa }\end{array}$ & $\begin{array}{l}\text { Symposide, } \\
\text { ellagic acid }\end{array}$ & $\begin{array}{l}\text { Anti fibrinolytic activity, } \\
\text { anti-inflammatory }\end{array}$ & $\begin{array}{l}\text { Controls } \\
\text { bleeding }\end{array}$ \\
\hline Haridra & $\begin{array}{l}\text { Curcuma } \\
\text { longa }\end{array}$ & Curcumin & $\begin{array}{l}\text { Analgesic, anti } \quad- \\
\text { inflammatory, } \\
\text { microbial }\end{array}$ & Reduces pain \\
\hline Yashtimadhu & $\begin{array}{l}\text { Glycyrrhiza } \\
\text { glabra }\end{array}$ & $\begin{array}{l}\text { Glycyrrhizin, } \\
\text { glycyrrhizic acid }\end{array}$ & analgesic effect & Reduces pain \\
\hline
\end{tabular}

\section{CONCLUSION:}

It is therefore concluded that Pylee capsule is a natural herbal product with multiple ingredients, appears to be a very useful preparation which helped in controlling bleeding, prolapse, pain and mucus discharge, and reduced the size of the pile mass in all degrees of piles. It would be an ideal product for management of piles offering total solution and frequent use may prevent re-occurrence of piles. It corrects the root cause of piles-constipation, inflammation, bleeding by strengthening vein walls. It shows anti -inflammatory and anti-infective properties which reduces infection naturally. Its natural laxative property corrects chronic constipation associated with haemorrhoids. It addresses all aspects of piles therapy.

\section{REFERENCES:}

1. Bharat Gami, Hemorrhoids - A Common Ailment Among Adults, Causes \& Treatment: A Review, 2011, International Journal of Pharmacy and Pharmaceutical Sciences ISSN- 0975-1491 Vol 3, Suppl 5.

2. https://www.news-medical.net/health/Epidemiology-of-Hemorrhoids.aspx

3. Dr. B. G. Rahul, International Surgery Journal: A Research article -Prevalence and risk factors of haemorrhoids: A study in a semi-urban centre 2018 Feb;5(2):496-499

4. Rajashree Rane, International Journal Of Institutional Pharmacy And Life Sciences, Analytical Evaluation of Ayurvedic Formulation Used In Management Of Piles 2015 | Volume 5 (3) | 41-51

5. T. Lakshmi, Vidya Krishnan, R. Rajendran, N. Madhusudhanan Pharmacognosy Review: Azadirachta indica- A herbal panacea- An update 2015 Jan -Jun; 9 (17): 41 44

6. Kausik Biswas, Ishita Chattopadhyay, Ranajit K. Banerjee and Uday Bandyopadhyay, Biological activities and medicinal properties of neem (Azadirachta indica), Current Science, Vol. 82, No. 11, 10 June 2002

7. Chhibber,S, Sharma, N, Medicinal and Therapeutically Potential of Neem (Azadirachta indica): A Review, International Journal of Scientific and Research Publications, Volume 4, Issue 5, 2014 
8. Rajani Chauhan, Km. Ruby, Jaya Dwivedi "Golden Herbs used in Piles Treatment: A Concise Report” Int. J. Drug Dev. \& Res., October-December 2012, 4(4): 50-68

9. Tamhane M D, Thorat S P, Rege N N, Dahanukar S A., Effect of oral administration of Terminalia chebula on gastric emptying: an experimental study. J Postgrad Med $1997 ; 43: 12$

10. Pampattiwar S P, Adwani N V, Bulusu Sitaram, Paramkusha Rao M, Pharmacological Study of Anti-Inflammatory Action of Haritaki Preparations on Wistar Rats in Hemorrhoids (Piles), Global J Res. Med. Plants \& Indigen. Med. | Volume 2, Issue 3 | March 2013 | 178-182

11. R. Dhaon, G.K. Jain, J.P.S. Sarin, N.M. Khanna, Symposide: a new anti fibrinolytic glycoside from Symplocos racemosa Roxb., Ind. J. Chem. 28B (1989), 982-983.

12. S. John, S. Nikhil, J. Yaswanth, A. Bhaskar, A. Amit, S. Sudha, Analgesic property of different extracts of Curcuma longa (Linn.): An experimental study in animals, Journal of Natural Remedies, Vol. 9/1 (2009) 116 - 120

13. S. Neha, G.D. Ranvir and C.R.Jangade, Analgesic and antipyretic activities of Curcuma longa rhizome extracts in Wister Rats, Veterinary World, Vol.2(8):304-306

14. Mohammad Hashem, An evidence based study on Medicinal plants for Hemorrhoids in Medieval Persia 2017 | Volume 2 (24) |969-981

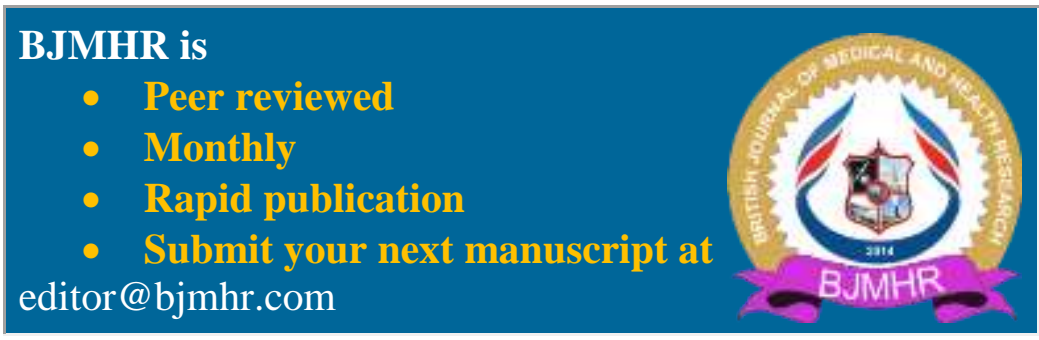

